\title{
Process Oriented Guided Inquiry Learning dalam Mereduksi Miskonsepsi Siswa SMA pada Materi Kesetimbangan Kelarutan
}

\author{
${ }^{1}$ Maria Erna, Sri Haryati, Anggie Oktaviani. S \\ Program Studi Pendidikan Kimia, Fakultas Keguruan dan Ilmu Pendidikan, Universitas Riau \\ Kampus Bina Widya Km 12, 5 Simpang Baru Pekanbaru, 28293, Indonesia \\ Email:1mariaerna@lecturer.unri.ac.id
}

Article History:

Received: 21-05-2020; Received in Revised: 05-12-2020; Accepted: 11-12-2020

\begin{abstract}
The application of the Process Oriented Guided Inquiry Learning (POGIL) strategy was carried out to reduce students' misconceptions on solubility equilibrium material. The design of this experimental study was a randomized control group pretest-posttest. The evaluation instrument used is a three-tier multiple-choice test using the Certainty of Response Index. The population of this study was 11-grade students one of the public schools in Pekanbaru city. The study sample was determined randomly after the normality test and homogeneity test was carried out. The experimental class was treated with the application of the POGIL learning strategy while the control class was without the implementation of the POGIL strategy. Data analysis for hypothesis testing is done using the right-party t-test. The results showed that tcount <ttable $(-0.59<2.02)$ can be interpreted that the application of the POGIL strategy can reduce students' misconceptions in the solubility equilibrium material with a reduction in misconceptions by $47.05 \%$.
\end{abstract}

Keywords: Equilibrium Solubility; Misconception; POGIL; Three Tier Multiple Choice Test.

\begin{abstract}
Abstrak
Penerapan strategi Process Oriented Guided Inquiry Learning (POGIL) dilakukan untuk mereduksi miskonsepsi siswa pada materi kesetimbangan kelarutan. Rancangan penelitian eksperimen ini adalah randomized control group pretest-posttest. Instrumen yang digunakan adalah tes pilihan ganda tiga tingkat dengan menggunakan Certainty of Response Index. Populasi penelitian ini adalah siswa kelas XI salah satu sekolah negeri di kota Pekanbaru. Sampel penelitian ditentukan secara acak setelah dilakukan uji normalitas dan uji homogenitas. Kelas eksperimen diberi perlakuan dengan penerapan strategi pembelajaran POGIL sedangkan kelas kontrol tanpa penerapan strategi POGIL. Analisa data untuk pengujian hipotesis dilakukan menggunakan uji-t pihak kanan. Hasil penelitian memperlihatkan thitung < tabel $(-0,59<2,02)$ dapat diartikan bahwa penerapan strategi POGIL dapat mereduksi miskonsepsi siswa pada materi kesetimbangan kelarutan dengan reduksi miskonsepsi sebesar $47,05 \%$.
\end{abstract}

Kata Kunci: Kesetimbangan Kelarutan; Miskonsepsi; POGIL; Tes Pilihan Ganda Tiga Tingkat. 


\section{Pendahuluan}

Proses pembelajaran berkaitan erat dengan masalah pendidikan. Pembelajaran dan pengajaran merupakan ujung tombak pendidikan². Pembelajaran melibatkan semua potensi yang dimiliki siswa dan guru agar tujuan pembelajaran dapat tercapai ${ }^{2}$. Dimyati dan Mudjiono menegaskan bahwa pembelajaran meliputi kegiatan guru yang terprogram untuk membuat siswa aktif selama belajar, sehingga guru menjadi fasilitator bagi siswa ${ }^{3}$. Siswa yang lebih mendominasi dalam kegiatan proses pembelajaran akan menyebabkan berlangsungnya transformasi pengetahuan, transformasi nilainilai dan transformasi keterampilan-keterampilan ${ }^{4}$.

Guru harus berupaya untuk menciptakan suasana pembelajaran kondusif yang dapat menuntun siswa bersifat aktif dan kreatif ${ }^{5}$. Suasana pembelajaran seperti ini akan memberikan harapan tercapainya hasil belajar yang lebih baik serta dapat memaksimalkan sejumlah kemampuan dan keterampilan siswa sehingga siswa mampu memecahkan masalah selama belajar6. Pemahaman konsep dalam suatu materi merupakan masalah yang sering dihadapi siswa. Hasil belajar yang kurang baik merupakan dampak dari pemahaman konsep yang kurang baik ${ }^{7}$. Salah satu mata pelajaran yang memerlukan pemahaman konsep yang baik adalah kimia ${ }^{8}$. Mata pelajaran kimia merupakan salah satu mata pelajaran yang kurang disukai siswa karena banyak mempelajari hal-hal yang abstrak. Menurut Gabel, pelajaran kimia merupakan pelajaran yang kompleks karena keabstrakannya9. Keabstrakan tersebut yang menyebabkan siswa sulit memahami kimia. Selain itu, Coll dan Taylor mengemukakan bahwa siswa sulit menghubungkan antara konsep mikroskopis dengan makrokospis dalam konsep kimiar ${ }^{10}$.

${ }^{1}$ Aprida Pane and Muhammad Darwis Dasopang, "Belajar Dan Pembelajaran," Fitrah: Jurnal Kajian IImu-IImu Keislaman 3, no. 2 (2017): 333-52.

2 Wina Sanjaya, Strategi Pembelajaran (Jakarta: Kencana Media Group, 2006).

3 Mudjiono Dimyati, Belajar Dan Pembelajaran (Jakarta: Rineka Cipta, 2006).

4 Novan Ardy Wiyani, Psikologi Perkembangan Anak Usia Dini (Yogyakarta: Gaya Media, 2014).

${ }^{5}$ Arianti Arianti, "Urgensi Lingkungan Belajar Yang Kondusif Dalam Mendorong Siswa Belajar Aktif," Didaktika: Jurnal Kependidikan 11, no. 1 (2019): 41-62.

${ }^{6}$ Sunhaji Sunhaji, "Konsep Manajemen Kelas Dan Implikasinya Dalam Pembelajaran," Jurnal Kependidikan 2, no. 2 (2014): 30-46, https://doi.org/10.24090/jk.v2i2.551.

${ }^{7}$ Fitriyane Laila Apriliani Rahmat, Suwatno Suwatno, and Rasto Rasto, "Meningkatkan Pemahaman Konsep Siswa Melalui Teams Games Tournament (Tgt): Meta Analisis," SOSIODIDAKTIKA: Social Science Education Journal 1, no. 1 (2018): 15-23.

${ }^{8}$ Novrita Mulya Rosa, "Pengaruh Sikap Pada Mata Pelajaran Kimia Dan Konsep Diri Terhadap Prestasi Belajar Kimia," Formatif: Jurnal IImiah Pendidikan MIPA 2, no. 3 (2015).

${ }^{9}$ Erika Ristiyani and Evi Sapinatul Bahriah, "Analisis Kesulitan Belajar Kimia Siswa Di SMAN X Kota Tangerang Selatan," Jurnal Penelitian Dan Pembelajaran IPA2, no. 1 (2016): 1829.

${ }^{10}$ Ibid. 
Menurut Andrade dan Schuiling, kesetimbangan kelarutan merupakan materi kimia kelas XI SMA yang membutuhkan pemahaman tinggi untuk menjawab pertanyaan terkait dengan materi tersebut. Diantaranya mengenai pengaruh $\mathrm{pH}$ dan ion senama terhadap kelarutan senyawa, perhitungan kelarutan, Qc dan kesetimbangan kelarutan suatu senyawa ${ }^{11}$. Krause dan Tasooji menyatakan bahwa sering terjadi miskonsepsi siswa dalam memahami materi kesetimbangan kelarutan, diantaranya siswa menganggap bahwa Kesetimbangan kelarutan senyawa tertentu pada temperature tertentu dapat berubah-ubah, dan didalam larutan lewat jenuh masih terdapat endapan ${ }^{12}$. Menurut Van Den Berg, miskonsepsi sangat berbahaya bagi siswa karena menyebabkan hasil belajar menurun dan salah konsep ${ }^{13}$. Miskonsepsi sangat penting untuk ditangani, oleh karena itu guru harus segera mencari penyelesaian tersebut agar siswa tidak mengalami miskonsepsi materi, salah satunya menggunakan strategi pembelajaran ${ }^{141516 .}$

Penelitian ini menggunakan strategi Process Oriented Guided Inquiry Learning (POGIL) yang berorientasi untuk membangun konsep materi yang benar sehingga dapat mengurangi miskonsepsi siswa ${ }^{17}$. Selain itu POGIL dirancang agar siswa lebih aktif sehingga pembelajaran berpusat pada siswa dan mengembangkan proses berpikir siswa dalam menemukan sendiri jawaban suatu permasalahan dari guru serta meningkatkan pemahaman siswa terhadap materi ${ }^{18}$. Herawati menyatakan bahwa belajar kimia pada dasarnya dimulai dengan mempelajari masalah yang berhubungan dengan kehidupan sehari-hari ${ }^{19}$. Permasalahan tersebut dikaitkan dengan pengetahuan kimia dan diharapkan dapat membangun pengertian dan pemahaman konsep kimia

${ }^{11}$ Nur Indah Firdausi, "Perbandingan Hasil Belajar Kimia Dengan Model Pembelajaran Inquiry Dan Learning Cycle 5e Pada Materi Kelarutan Dan Hasil Kali Kelarutan," Jurnal Pendidikan Sains 2, no. 4 (2014): 193-99.

12 Ibid.

13 Euwe Van Den Berg, "Miskonsepsi Fisika Dan Remediasi," Salatiga: Universitas Kristen Satya Wacana, 1991.

14 Vinsenia Ade Sugiawati, "Penggunaan Strategi Konflik Kognitif Dalam Pembelajaran TPS untuk Mereduksi Miskonsepsi Siswa pada Materi Termokimia," JURNAL NALAR PENDIDIKAN1, no. 1 (November 1, 2013), https://doi.org/10.26858/jnp.v1i1.1935.

15 Alvi Dwi Puri Rahayu, "Penerapan Strategi Konstruktivis Untuk Mereduksi Miskonsepsi Level Sub-Mikroskopik Siswa Pada Materi Kesetimbangan Kimia Kelas XI SMA Hang Tuah 2 Sidoarjo," Unesa Journal Of Chemical Education 3, no. 2 (2014): 88-98.

${ }^{16}$ Kristin Lintong, Nurhayati Bialangi, and Masrid Pikoli, "Pengaruh Penerapan Strategi Pogil Terhadap Reduksi Miskonsepsi Siswa Pada Konsep Redoks Di SMA Negeri 1 Tapa," Jambura Journal of Educational Chemistry 13, no. 2 (2018): 215-20.

17 Ibid.

18 Anis Sulalah Bm, "Implementasi Strategi Pogil untuk Mereduksi Miskonsepsi pada Materi Stoikiometri Kelas X di SMAN 1 Kandangan," UNESA Journal of Chemical Education 3, no. 3 (September 30, 2014), https://jurnalmahasiswa.unesa.ac.id/index.php/journal-ofchemical-education/article/view/9763.

19 Warsono and Hariyanto, Pembelajaran Aktif Teori Dan Asesmen (Bandung: Remaja Rosdakarya, 2012). 
lebih bermakna. Hal ini terjadi karena siswa membentuk sendiri struktur pengetahuan yaitu konsep kimia melalui bantuan dan bimbingan guru.

Menurut Warsono dan Hariyanto, strategi POGIL menerapkan suatu metode yang berlandaskan pembelajaran berbasis siswa (student-centered) dan suatu struktur yang secara konsisten menyajikan bagaimana cara siswa belajar dan mencapai hasil pembelajarannya ${ }^{20}$. Melalui pembelajaran dengan strategi POGIL memberi kesempatan kepada siswa untuk aktif mengkonstruksi pemahaman mereka dalam diskusi kelompok ${ }^{21}$. Strategi POGIL terdapat tiga fase yaitu eksplorasi, penemuan atau pembentukan konsep, dan aplikasi. Strategi POGIL mempunyai kelebihan yaitu: a) kegiatan selama proses pembelajaran lebih terstruktur, terkendali dan terarah, b) tercapainya tujuan pembelajaran, c) waktu belajar lebih efektif ${ }^{22}$. Berdasarkan penelitian yang dilakukan Anis Sulalah pada materi Stoikiometri dinyatakan bahwa strategi pembelajaran POGIL menggunakan model pembelajaran inkuiri terbimbing dapat mengembangkan pemahaman siswa dalam proses pembelajaran sehingga terjadi reduksi miskonsepsi siswa pada materi Stoikimetri ${ }^{23}$.

Penelitian ini dilakukan di salah satu sekolah negeri kota Pekanbaru. Hasil wawancara dengan guru menyatakan bahwa pada saat proses pembelajaran kimia, siswa yang aktif biasanya siswa yang termasuk kategori tinggi secara akademis. Hal ini menyebabkan jumlah siswa yang ketuntasan belajarnya mencapai nilai KKM tidak sampai 100\% dan teridentifikasi oleh guru bahwa banyak siswa yang mengalami miskonsepsi tentang kesetimbangan kelarutan karena ketidaktauan dengan konsep yang benar. Hasil penelitian ini penting dan diharapkan dapat diterapkan pada materi kimia yang lain serta untuk mereduksi miskonsepsi siswa pada materi kesetimbangan kelarutan.

\section{Metode}

Penelitian ini menerapkan strategi POGIL pada materi kesetimbangan larutan di salah satu sekolah negeri di kota Pekanbaru. Jenis penelitian yang digunakan adalah penelitian eksperimen dengan rancangan penelitian Design

20 Ibid.a

21 Yanuarin Nisaur Rohmah, "Penerapan Pembelajaran Dengan Strategi Pogil Pada Materi Pokok Kelarutan Dan Hasil Kali Kelarutan Untuk Melatih Kemampuan Berpikir Kritis Siswa Kelas XI SMA Negeri 1 Sooko Mojokerto," UNESA Journal of Chemical Education 2, no. 3 (2013).

22 Vanesha Dewi Alamanda, "Penerapan Strategi Pogiluntuk Meningkatkan Self-Efficacy Siswa Pada Materi Ikatan Kimia Kelas X (Implementation of Strategies Pogil to Improve Student's Self-Efficacyon Chemical Bonding Material in Class X)," UNESA Journal of Chemical Education 4, no. 1 (2015).

23 Ibid. 
Randomized Control Group Pretest-Posttest sebagaimana yang terlihat pada Tabel $1^{24}$.

Tabel 1. Rancangan Penelitian

\begin{tabular}{cccc}
\hline Kelas & Nilai Pretest & Perlakuan & Nilai Postest \\
\hline Eksperimen & $\mathrm{T}_{1}$ & $\mathrm{X}$ & $\mathrm{T}_{2}$ \\
\hline Kontrol & $\mathrm{T}_{1}$ & - & $\mathrm{T}_{2}$ \\
\hline
\end{tabular}

Keterangan :

$\mathrm{T}_{1}=$ Nilai pretest kelas eksperimen dan kelas kontrol

$\mathrm{X}=$ Perlakuan terhadap kelas eksperimen dengan penerapan strategi pembelajaran POGIL

$\mathrm{T}_{2}=$ Nilai posttest kelas eksperimen dan kelas kontrol

Distribusi data yang diguankan pada penelitian ini diuji menggunakan cara Liliefors. Jika $L_{\text {maks }} \leq L_{\text {tabel }}$ maka data dikatakan terdistribusi normal dengan kriteria pengujian $(\alpha=0,05)$. Harga $L_{\text {tabel }}$ diperoleh dengan persamaan berikut ${ }^{25}$ :

$$
L_{\text {tabel }}=\frac{0,886}{\sqrt{n}}
$$

Homogenitas data digunkan uji F dengan persamaan berikut:

$$
F=\frac{\text { Variansi Terbesar }}{\text { Variansi Terkecil }}
$$

Jika $F_{\text {hitung }}<F_{\text {tabel, }}$ maka kedua sampel dikatakan homogen dengan nilai $\alpha$ $=0,05$. Sedangkan uji hipotesis dilakukan dengan menggunakan uji-t pihak kanan dengan persamaan berikut:

$$
t=\frac{\bar{x}_{1}-\bar{x}_{2}}{S_{g} \sqrt{\frac{1}{n_{1}}+\frac{1}{n_{2}}}}
$$

Jika thitung $<t_{\text {tabel }}$ maka hipotesis diterima dan jika harga $t$ lainnya hipotesis ditolak ${ }^{26}$.

Intrumen tes (pretest maupun postest) yang digunakan pada penelitian ini adalah Three Tier Multiple Choice dengan menggunakan Certainty of Response Index (CRI). Hasil tes dapat dikelompokkan ke dalam empat

${ }^{24}$ Sugiyono, Metode Penelitian Kuantitaf Kualitatif Dan R\&D (Bandung: Alfabeta, 2012).

25 Rostina Sundayana, Statistika Penelitian Pendidikan (Bandung: Alfabeta, 2014).

${ }^{26}$ Sudjana, Metode Statistika (Bandung: PT. Tarsito, 2005). 
keputusan dan dapat dilihat pada Tabel $2^{272829}$. Skor setiap butir soal dapat dilihat pada Tabel 3.

Tabel 2. Kriteria Pengelompokan Konsepsi Siswa

\begin{tabular}{ccll}
\hline Tingkat 1 & Tingkat 2 & Tingkat 3 (CRI) & \multicolumn{1}{c}{ Keputusan } \\
\hline Benar & Benar & Yakin & Tahu Konsep \\
Benar & Benar & Tidak Yakin & Menebak \\
Benar & Salah & Yakin & Miskonsepsi \\
Benar & Salah & Tidak Yakin & Menebak \\
Salah & Salah & Yakin & Miskonsepsi \\
Salah & Salah & Tidak Yakin & Tidak Tahu Konsep \\
Salah & Benar & Yakin & Miskonsepsi \\
Salah & Benar & Tidak Yakin & Menebak \\
\hline
\end{tabular}

Tabel 3. Skor Butir Soal

\begin{tabular}{ccl}
\hline Bentuk soal & Nilai & \multicolumn{1}{c}{ Keterangan } \\
\hline \multirow{2}{*}{ Tes Multiple Choice } & 1 & Benar \\
& 0 & Salah \\
\hline
\end{tabular}

Untuk menentukan persentase miskonsepsi yang terjadi digunakan peramaan berikut ini:

$$
\begin{aligned}
\% T K & =\frac{T K}{N} \times 100 \% \\
\% T T K & =\frac{T T K}{N} \times 100 \% \\
\% M K & =\frac{M K}{N} \times 100 \% \\
\% M B & =\frac{M B}{N} \times 100 \%
\end{aligned}
$$

Dengan :

$$
\begin{array}{ll}
\text { TK } & =\text { Tahu konsep } \\
\text { TTK } & =\text { Tidak tahu konsep } \\
\text { MK } & =\text { Miskonsepsi } \\
\text { MB } & =\text { Menebak jawaban } \\
\text { N } & =\text { Jumlah seluruh siswa }
\end{array}
$$

27 Yuyu R Tayubi, “Identifikasi Miskonsepsi Pada Konsep-Konsep Fisika Menggunakan Certainty of Response Index (CRI)," Mimbar Pendidikan, no. 3 (2005): 6.

28 Friesta Ade Monita and Bambang Suharto, "Identifikasi Dan Analisis Miskonsepsi Siswa Menggunakan Three-Tier Multiple Choice Diagnostic Instrument Pada Konsep Kesetimbangan Kimia," Quantum: Jurnal Inovasi Pendidikan Sains 7, no. 1 (2016): 27-38.

${ }_{29}$ Elsa Meriani Waluyo, Arif Muchyidin, and Hadi Kusmanto, "Analysis of Students Misconception in Completing Mathematical Questions Using Certainty of Response Index (CRI)," Tadris: Jurnal Keguruan Dan IImu Tarbiyah 4, no. 1 (June 30, 2019): 27-39, https://doi.org/10.24042/tadris.v4i1.2988. 
Untuk penentuan besarnya reduksi miskonsepsi dilakukan dengan cara membandingkan hasil rata-rata miskonsepsi pada kelas eksperimen dengan kelas kontrol.

\section{Hasil dan Diskusi}

Reduksi miskonsepsi yang ditemukan pada penelitian ini merupakan selisih dari persentase nilai pretest dan posttest dari masing-masing sampel yang datanya terdistrubusi normal dan homogen. Pada penelitian ini setiap butir soal dianalisis untuk melihat kemampuan pemahaman konsep siswa. Pada Gambar 1, memperlihatkan bahwa secara keseluruhan terjadi reduksi miskonsepsi pada setiap butir soal maupun konsep, reduksi miskonsepsi tertinggi terjadi pada soal nomor sebesar 77\% mengenai konsep menjelaskan hubungan kelarutan dan hasil kali kelarutan. Soal nomor 6 sebagian besar siswa memahami konsep bahwa semakin besar harga kesetimbangan kelarutan maka semakin besar pula kelarutan suatu senyawa, maka pada soal nomor 6 sebagian besar siswa menjawab pilihan D (jawaban miskonsepsi). Namun, pada dasarnya konsep ini hanya berlaku pada senyawa yang memiliki jumlah ion yang sama karena harga kelarutan dan hasil kali kelarutan dipengaruhi oleh koefisien ion pada senyawa tersebut. Sedangkan, pada nomor 10 menjelaskan tentang memprediksi terbentuknya endapan berdasarkan perbandingan Qsp dan Ksp sebagian siswa menjawab pilihan C (jawaban miskonsepsi).

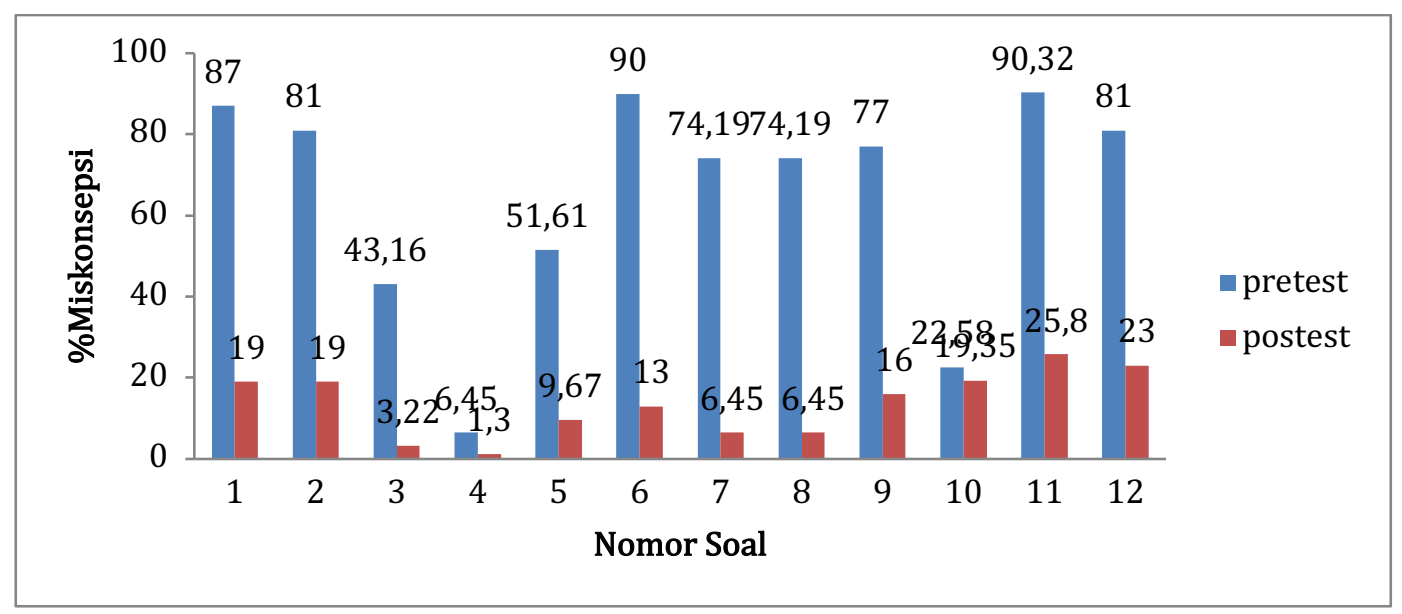

Gambar 1. Persentase Reduksi Miskonsepsi per Butir Soal Kelas Eksperimen

Reduksi miskonsepsi siswa antara kelas kontrol dan eksperimen pada materi kesetimbangan kelarutan di kelas XI MIA SMA Negeri 11 Pekanbaru dapat dilihat pada Gambar 2. 


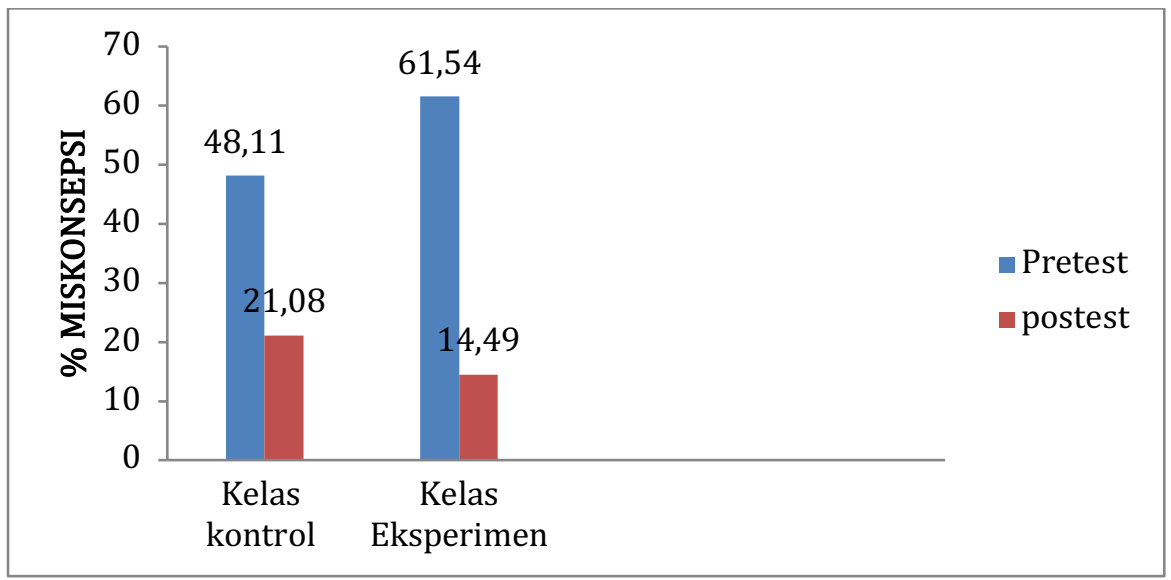

Gambar 2. Persentase Rata-Rata Reduksi Miskonsepsi Siswa

Terlihat pada Gambar 2, bahwa strategi POGIL yang diterapkan pada kelas eksperimen mereduksi miskonsepsi lebih tinggi dibandingkan pada kelas kontrol tanpa strategi POGIL. Pada kelas eksperimen terjadi reduksi miskonsepsi siswa sebesar $47,05 \%$, data ini diperoleh dari selisih rata-rata miskonsepsi pretest $61,54 \%$ dengan rata-rata miskonsepsi posttest $14,49 \%$. Sedangkan pada kelas kontrol terjadi reduksi miskonsepsi siswa sebesar $27,03 \%$.

Strategi POGIL dipilih untuk mereduksi miskonsepsi karena langkahlangkah strategi POGIL dapat membuat siswa lebih aktif dan bertanggung jawab terhadap peran mereka dalam kelompok. Melalui kerja sama dalam tim untuk menyelesaikan soal dan masalah dari guru, siswa lebih dapat menguasai materi pembelajaran. Strategi POGIL bertujuan agar siswa memiliki keterampilan efektif karena siswamempunyai tugas masing-masing yaitu sebagai manager, strategy analyst, recorder, speaker person. Guru membagikan kelompok tersebut sebelum proses pembelajaran dimulai. Pembagian tugas kelompok bertujuan agar siswa bertanggung jawab dengan tugas masing-masing dan mudah memahami konsep dengan teman sebaya. Hal tersebut dapat meningkatkan kemampuan belajar. Keaktifan dilihat dari banyaknya siswa bertanya mengenai soal maupun masalah yang belum dipahami. Belajar bersama dalam tim dapat membuat penalaran meningkat ke tingkat yang lebih tinggi, karena pada strategi POGIL terdapat peran masingmasing anggota kelompok sehingga belajar jadi lebih menarik dan siswa aktif selama proses pembelajaran ${ }^{30}$.

Pembelajaran menggunakan strategi POGIL membantu siswa mengembangkan pengetahuan/pemahamannya sendiri melalui tahap eksplorasi tujuannya mengetahui bahwa siswa sudah memiliki pengetahuan

30 Patrick JP Brown, "Process-Oriented Guided-Inquiry Learning in an Introductory Anatomy and Physiology Course with a Diverse Student Population," Advances in Physiology Education 34, no. 3 (2010): 150-55. 
awal melalui wacana. Adanya penyajian wacana tujuannya agar siswa tertarik dan memiliki motivasi untuk belajar sehingga pembelajaran lebih mudah dipahami. Perhatian dan motivasi merupakan faktor penentuan berhasil atau tidak siswa dalam belajar ${ }^{31}$.

Barthlow juga menyatakan bahwa konsep alternatif materi kimia berkurang dengan menerapkan strategi POGIL ${ }^{32}$. Strategi POGIL berpusat pada siswa untuk membangun kemampuan kognitif sendiri setelah dilatihkan keterampilan sains sehingga konsepsi alternatif materi kimia dapat direduksi.

Tahap penemuan dan pembentukan konsep, siswa dipandu guru untuk menemukan konsep. Guru merupakan fasilitator yang mendorong dan memacu siswa agar dapat menjawab pertanyaan di LKPD selama proses pembelajaran berlangsung. Tahap ini, siswa dipandu guru berdiskusi dan menjawab pertanyaan di LKPD pada bagian penemuan konsep. Sebagai contoh pada pertemuan pertama, setelah membaca wacana, siswa menjawab pertanyaandi LKPD. Tahap penemuan dan pembentukan konsep ini, melatih kemampuan berpikir siswa. Berkembangnya pemahaman konsep diketahui setelah siswa menjawab berbagai pertanyaan ${ }^{33}$.

Tahap aplikasi, siswa dipandu oleh guru menjawab latihan pemecahan masalah aplikasi konsep pada LKPD. Latihan pemecahan masalah tersebut berupa soal dan membutuhkan penalaran tinggi untuk menjawabnya. Tahap eksplorasi, penemuan konsep dan aplikasi dibuktikan dari hasil pekerjaan LKPD siswa. Tahapan dalam strategi POGIL ini bertujuan untuk meningkatkan pemahaman dan kemampuan berfikir siswa. Jika pada tahap sebelumnya siswa menjawab pertanyaan dengan benar maka dapat diartikan kemampuan berpikir dan pemahaman siswa meningkat. Peran guru pada strategi POGIL yaitu membimbing, menuntun, serta membantu siswa mengembangkan pemahamannya sendiri setelah belajar ${ }^{34}$.

Miskonsepsi ini berdampak buruk bagi siswa, sehingga miskonsepsi yang terjadi harus diperbaiki ${ }^{35}$. Prakonsepsi awal yang salah merupakan penyebab utama terjadinya miskonsepsi pada siswa. Miskonsepsi siswa dapat disebabkan karena metode mengajar yang membosankan dan kurang

31 Ibid.

32 Michelle J. Barthlow and Scott B. Watson, "The Effectiveness of Process-Oriented Guided Inquiry Learning to Reduce Alternative Conceptions in Secondary Chemistry," School Science and Mathematics 114, no. 5 (2014): 246-55.

33 David M. Hanson, Instructor's Guide to Process Oriented Guided Inquiry Learning (New York: Pacific Crest, 2013).

34 Adelia Alfama Zamista and Ida Kaniawati, "Pengaruh Model Pembelajaran Process Oriented Guided Inquiry Learning Terhadap Keterampilan Proses Sains dan Kemampuan Kognitif Siswa pada Mata Pelajaran Fisika," EDUSAINS 7, no. 2 (2015): 191-201, https://doi.org/10.15408/es.v7i2.1815.

35 Ahmad Ahmad, Suyono Suyono, and Leny Yuanita, "Reduksi Miskonsepsi Asam Basa Melalui Inkuiri Terbuka Dan Strategi Conceptual Change," JPPS (Jurnal Penelitian Pendidikan Sains) 3, no. 1 (2017): 286-93. 
bervariasi $^{36}$. Apabila konsep awal yang dimiliki siswa salah, maka akan mengakibatkkan terjadi kesalahan konsep pada tingkat berikutnya. Sehingga terjadi rantai kesalahan konsep yang tidak terputus ${ }^{36}$.

Berdasarkan hasil penelitian dapat dilihat bahwa penerapan strategi POGIL mereduksi miskonsepsi pada kelas ekskperimen sebesar 47,05\%. Data ini diperoleh dari selisih rata-rata miskonsepsi pretest $61,54 \%$ dengan ratarata miskonsepsi posttest $14,49 \%$. Strategi POGIL membantu siswa untuk mengembangkan pemahaman konsep sehingga persentase miskonsepsi siswa menurun. Strategi POGIL melatih siswa memiliki kemampuan berpikir tingkat tinggi, memecahkan masalah, dan berkomunikasi sehingga dapat membantu siswa untuk menguasai konsep pada materi kimia. Strategi ini juga membantu siswa untuk memahami fenomena kimia yang abstrak melalui suatu model yang berupa fenomena. Fenomena kehidupan sehari-hari yang berhubungan dengan materi pokok kesetimbangan kelarutan dapat dimunculkan dalam pemodelan.

\section{Kesimpulan}

Strategi POGIL yang diterapkan dalam pembelajaran kimia dapat mereduksi miskonsepsi siswa pada materi kesetimbangan kelarutan di kelas XI salah satu sekolah negeri kota Pekanbaru sebesar 47,05\%. Reduksi miskonsepsi tertinggi terjadi pada butir soal nomor 6 sebesar 77\%. Strategi POGIL melatih siswa memiliki kemampuan berpikir tingkat tinggi, memecahkan masalah, dan berkomunikasi. Siswa juga dapat memahami fenomena kimia yang abstrak melalui suatu model fenomena.

\section{Ucapan Terimakasih}

Terima kasih kepada Universitas Riau yang telah memfasilitasi penelitian ini melalui Lembaga Penelitian dan pengabdian kepada Masyarakat dengan skim penelitian bidang ilmu.

\section{Daftar Pustaka}

Ahmad, Ahmad, Suyono Suyono, and Leny Yuanita. "Reduksi Miskonsepsi Asam Basa Melalui Inkuiri Terbuka dan Strategi Conceptual Change." JPPS (Jurnal Penelitian Pendidikan Sains)3, No. 1 (2017): 286-93.

Arianti, Arianti. "Urgensi Lingkungan Belajar Yang Kondusif Dalam Mendorong Siswa Belajar Aktif.” Didaktika: Jurnal Kependidikan 11, No. 1 (2019): 41-62.

36 Nurlela Nurlela, Mawardi Mawardi, and Tuti Kurniati, "Kajian Miskonsepsi Siswa Melalui Tes Multiple Choice Menggunakan Certainty of Response Index (CRI) Pada Materi Reaksi Reduksi Oksidasi Kelas X MIPA SMAN 1 Pontianak," Ar-Razi Jurnal Ilmiah 5, no. 2 (2017). 
Barthlow, Michelle J., and Scott B. Watson. "The Effectiveness of ProcessOriented Guided Inquiry Learning to Reduce Alternative Conceptions in Secondary Chemistry." School Science and Mathematics 114, No. 5 (2014): 246-55.

Berg, Euwe Van Den. "Miskonsepsi Fisika dan Remediasi." Salatiga: Universitas Kristen Satya Wacana, 1991.

Bm, Anis Sulalah. "Implementasi Strategi Pogil untuk Mereduksi Miskonsepsi pada Materi Stoikiometri Kelas X di SMAN 1 Kandangan." UNESA Journal of Chemical Education 3, No. 3 (September 30, 2014). https://jurnalmahasiswa.unesa.ac.id/index.php/journal-of-chemicaleducation/article/view/9763.

Brown, Patrick JP. "Process-Oriented Guided-Inquiry Learning in an Introductory Anatomy and Physiology Course with a Diverse Student Population." Advances in Physiology Education 34, No. 3 (2010): 15055.

Dewi Alamanda, Vanesha. "Penerapan Strategi Pogiluntuk Meningkatkan SelfEfficacy Siswa Pada Materi Ikatan Kimia Kelas X (Implementation of Strategies Pogil to Improve Student's Self-Efficacyon Chemical Bonding Material in Class X)." UNESA Journal of Chemical Education 4, no. 1 (2015).

Dimyati, Mudjiono. Belajar dan Pembelajaran. Jakarta: Rineka Cipta, 2006.

Firdausi, Nur Indah. "Perbandingan Hasil Belajar Kimia Dengan Model Pembelajaran Inquiry dan Learning Cycle 5e Pada Materi Kelarutan dan Hasil Kali Kelarutan." Jurnal Pendidikan Sains 2, no. 4 (2014): 193-99.

Hanson, David M. Instructor's Guide to Process Oriented Guided Inquiry Learning. New York: Pacific Crest, 2013.

Lintong, Kristin, Nurhayati Bialangi, and Masrid Pikoli. "Pengaruh Penerapan Strategi Pogil Terhadap Reduksi Miskonsepsi Siswa Pada Konsep Redoks Di SMA Negeri 1 Tapa." Jambura Journal of Educational Chemistry13, No. 2 (2018): 215-20.

Monita, Friesta Ade, and Bambang Suharto. "Identifikasi Dan Analisis Miskonsepsi Siswa Menggunakan Three-Tier Multiple Choice Diagnostic Instrument Pada Konsep Kesetimbangan Kimia." Quantum: Jurnal Inovasi Pendidikan Sains 7, No. 1 (2016): 27-38.

Nurlela, Nurlela, Mawardi Mawardi, and Tuti Kurniati. "Kajian Miskonsepsi Siswa Melalui Tes Multiple Choice Menggunakan Certainty of Response Index (CRI) Pada Materi Reaksi Reduksi Oksidasi Kelas X MIPA SMAN 1 Pontianak." Ar-Razi Jurnal Ilmiah 5, No. 2 (2017).

Pane, Aprida, and Muhammad Darwis Dasopang. "Belajar Dan Pembelajaran." Fitrah: Jurnal Kajian IImu-IImu Keislaman 3, No. 2 (2017): 333-52.

Rahayu, Alvi Dwi Puri. "Penerapan Strategi Konstruktivis Untuk Mereduksi Miskonsepsi Level Sub-Mikroskopik Siswa Pada Materi Kesetimbangan Kimia Kelas XI SMA Hang Tuah 2 Sidoarjo." Unesa Journal Of Chemical Education 3, No. 2 (2014): 88-98.

Rahmat, Fitriyane Laila Apriliani, Suwatno Suwatno, and Rasto Rasto. "Meningkatkan Pemahaman Konsep Siswa Melalui Teams Games 
Tournament (Tgt): Meta Analisis." SOSIO-DIDAKTIKA: Social Science Education Journal 1, No. 1 (2018): 15-23.

Ristiyani, Erika, and Evi Sapinatul Bahriah. "Analisis Kesulitan Belajar Kimia Siswa Di SMAN X Kota Tangerang Selatan." Jurnal Penelitian Dan Pembelajaran IPA 2, No. 1 (2016): 18-29.

Rohmah, Yanuarin Nisaur. "Penerapan Pembelajaran Dengan Strategi Pogil Pada Materi Pokok Kelarutan Dan Hasil Kali Kelarutan Untuk Melatih Kemampuan Berpikir Kritis Siswa Kelas XI SMA Negeri 1 Sooko Mojokerto." UNESA Journal of Chemical Education 2, No. 3 (2013).

Rosa, Novrita Mulya. "Pengaruh Sikap Pada Mata Pelajaran Kimia Dan Konsep Diri Terhadap Prestasi Belajar Kimia." Formatif: Jurnal IImiah Pendidikan MIPA 2, No. 3 (2015).

Sudjana. Metode Statistika. Bandung: PT. Tarsito, 2005.

Sugiawati, Vinsenia Ade. "Penggunaan Strategi Konflik Kognitif Dalam Pembelajaran TPS untuk Mereduksi Miskonsepsi Siswa pada Materi Termokimia." Jurnal Nalar Pendidikan 1, No. 1 (November 1, 2013). https://doi.org/10.26858/jnp.v1i1.1935.

Sugiyono. Metode Penelitian Kuantitaf Kualitatif dan R\&D. Bandung: Alfabeta, 2012.

Sundayana, Rostina. Statistika Penelitian Pendidikan. Bandung: Alfabeta, 2014.

Sunhaji, Sunhaji. "Konsep Manajemen Kelas dan Implikasinya Dalam Pembelajaran." Jurnal Kependidikan 2, No. 2 (2014): 30-46. https://doi.org/10.24090/jk.v2i2.551.

Tayubi, Yuyu R. "Identifikasi Miskonsepsi Pada Konsep-Konsep Fisika Menggunakan Certainty of Response Index (CRI)." Mimbar Pendidikan, No. 3 (2005): 6.

Waluyo, Elsa Meriani, Arif Muchyidin, and Hadi Kusmanto. "Analysis of Students Misconception in Completing Mathematical Questions Using Certainty of Response Index (CRI)." Tadris: Jurnal Keguruan Dan Ilmu Tarbiyah 4, No. 1 (June 30, 2019): 27-39. https://doi.org/10.24042/tadris.v4i1.2988.

Warsono and Hariyanto. Pembelajaran Aktif Teori dan Asesmen. Bandung: Remaja Rosdakarya, 2012.

Wina Sanjaya. Strategi Pembelajaran. Jakarta: Kencana Media Group, 2006.

Wiyani, Novan Ardy. Psikologi Perkembangan Anak Usia Dini. Yogyakarta: Gaya Media, 2014.

Zamista, Adelia Alfama, and Ida Kaniawati. "Pengaruh Model Pembelajaran Process Oriented Guided Inquiry Learning Terhadap Keterampilan Proses Sains dan Kemampuan Kognitif Siswa pada Mata Pelajaran Fisika." EDUSAINS 7, No. 2 (2015): 191-201. https://doi.org/10.15408/es.v7i2.1815. 